\title{
Personality and emotional maturity of depressive and obsessive compulsive disorders
}

\author{
Dr. Thiyam Kiran Singh*, Akanksha Sharma**
}

\begin{abstract}
In this study random sampling technique was used in which a sample of 30 Depressive patients and 30 Obsessive Compulsive Disorder (OCD) patients were collected with the age range of 18 to 40 years. The participants were administered Dimensional Personality Inventory developed by Bhargav (1997) and Emotional Maturity Scale developed by Singh and Bhargave (1991). The purpose of the study is to compare Depressive and OCD patients on Personality Inventory Test and Emotional Maturity Scale to find out any significant difference in overall personality and its various dimensions similarly as well as overall Emotional Maturity and its various dimensions. The result found no significant in overall personality and its dimensions. Likewise, the result also found no significant difference in overall Emotional maturity but there is significant difference under the dimensions of Emotional Progression and Independence which gives the impression that depressive patients are more emotionally progressed or improved but less independent comparing with O.C.D. patients.
\end{abstract}

Key words: - Depression, Obsessive-Compulsive Disorder, Personality, Emotional Maturity.

As emotions do play central role in the life of an individual, one is expected to have higher emotional maturity in order to lead an effective life. It is also true that our behaviour is constantly influenced by the emotional maturity level that we possess. Emotional maturity allows handling life's ups and downs without over reacting. Emotional maturity is a process in which the personality is continuously striving for greater sense of emotional health both intra-physically and intrapersonally. However, when emotions become intense and unremitting and are not tied to a particular stimulus, they are called moods and extreme and persistent moods can lead to depression. Emotions exert an incredibly powerful force on human behavior. Strong emotions can cause you to take actions you might not normally perform or avoid situations that you generally enjoy. Why exactly do we have emotions? What causes us to have these feelings? Researchers, philosophers and psychologists have proposed a number of different theories to explain the how and why behind human emotions. In psychology, emotion is often defined as a complex state of feeling that results in physical and psychological changes that influence thought and behavior. Emotionality is associated with a range of psychological phenomena including temperament, personality, mood and motivation. According to author David G. Meyers, human emotion involves "Physiological arousal, expressive behaviors and conscious experience."

*M.A., M.Phil (M\&SP), Ph.D (Clinical Psychology), Assistant Professor, Dept. of Psychology, AIBAS, Amity University Rajasthan.

**M.Phil Clinical Psychology trainees. AIBAS, Amity University Rajasthan. 
The word "emotion" comes from dates back to 1579 when it was adapted from the French word émouvoir, which means "to stir up". In psychology there are three main reasons to study emotion: 1. To understand emotion. 2. To understand expression of emotion. 3. To use methods of control emotion. In world today, to know and to measure Intelligence Quotient (IQ) is very famous. Likewise, after study of Emotional Quotient (EQ) by Daniel Goldman, EQ is also becomes famous (Gopani, 2013). The present study has attempted to compare personality and emotional maturity of Depressive and Obsessive Compulsive Disorder (OCD) patients so as to gain knowledge about personality and emotional maturity and could implement in helping them in treatment once we get idea about the difference of personality and emotional maturity between Depressive patients and OCD patients using positive therapy as Menon (2011) mentioned that positive therapy have been successfully conducted in managing Stress, Depression, Anxiety and Anger.

\section{OBJECTIVES:}

1. To compare the Depressive and obsessive compulsive disorder (OCD) patients on personality and its various dimensions i.e. activity-passivity, enthusiastic-non enthusiastic, assertivesubmissive, suspicious-trusting, depressive-non depressive and emotional instability-emotional stability.

2. To compare the depressive and obsessive compulsive disorder patients on emotional maturity and its various dimensions i.e. emotional stability, emotional progression, social adjustment, personality integration and independence.

\section{HYPOTHESIS:}

1. There will be significant difference in comparison between Depressive and OCD patients on Dimensional Personality Inventory (DPI).

2. There will be significant difference in comparison between Depressive and OCD patients on Emotional Maturity Scale (EMS).

\section{DEPRESSIVE PATIENT: \\ Inclusion Criteria:}

1. Age range between 18 to 40 years.

2. Those fulfilled diagnostic criteria of Depression according to ICD-10.

\section{Exclusion Criteria:}

1. Age below 18 and above 40 years.

2. Those can't cooperate for study.

Obsessive and Compulsive Disorder (OCD) Patients:

\section{Inclusion Criteria:}

1. Age range between 18 to 40 years.

2. Those fulfilled diagnostic criteria of Depression according to ICD-10.

Exclusion Criteria:

1. Age below 18 and above 40 years.

2. Those can't cooperate for study. 
The International Journal of Indian Psychology: Volume: 01 | Issue: 04 | ISSN 2348-5396

\section{METHODOLOGY:}

Sample: - The sample consisted of 60 patients. The age varies from 18 to 40 years. All sixty patients (Depressive patients $=30$ and OCD patients $=30$ ) were draw using the technique of simple random sampling.

\section{TOOLS USED:}

\section{Dimensional Personality Inventory (DPI):}

This scale was developed by Bhargav (1997) which consisted of 60 statements in Hindi and English. It measures six personality dimensions each dimension is measured by 10 items through three response alternatives i.e. Yes, Undecided and No and dimensions are activitypassivity trait, enthusiastic-non enthusiastic trait, assertive-submissive, suspicious-trusting, depressive-non depressive and emotional instability- emotional stability. The reliability of DPI is determined by the test-retest and split half method and was found to be lowest 0.39 and highest 0.63 which ensures the high reliability. It also yields satisfactory validity. DPI was correlated with the same personality traits of English version of Sen et al. (2005) personality trait inventory (PTI) on a sample of 80 and obtained validity coefficients were 0.66 and 0.84 .

\section{Emotional Maturity Scale (EMS):}

Emotional Maturity Scale was developed by Singh and Bhargava (1991). This scale measures a list of five broad factors of Emotional Immaturity - Emotional Unstability, Emotional regression, social maladjustment, personality disintegration and lack of independence. It is a selfreporting five point scale. Items of the scale are in question form demanding information for each in any of the 5 options: Always, Mostly, Uncertain, Usually, Never. The items were scored as 5, 4, 3, 2 and 1 respectively. Therefore, the higher the score on the scale leads greater the degree of emotional immaturity and vice versa. The scale has total 48 items. There are 10 items per factor except the fifth factor which has 8 items. The highest possible score for the first 4 areas are 50 and the lowest is 10 while for the fifth factor the highest score is 40 and lowest is 8.(For all the first 4 factors the extremely unstable range from 10-20 ( for 5 th factor-8-16), moderately unstable from 21-30 (17-24), unstable from 31-40 (25-32), stable from 41-50(33-40). Reliability of the scale was determined by test retest reliability which was 0.75 and internal consistency for various factors ranged from .42-.86. The scale was validated against external criteria, i.e. .the area of the adjustment inventory for college students (Sinha and Singh, 1995).

\section{Procedure:}

The total samples of 60 were collected out of which 30 were Depressive patients and 30 were OCD patients. These samples were collected using simple random sampling method from those patients who were cooperative and ready to give consent for study. These samples were taken from Mental Hospital Bareilly. All patients who are included in study were administered Dimensional Personality Inventory and Emotional Maturity Scale to assess their personality and emotional maturity of their life. All the participants were given consent form to read before participation in the study.

\section{STATISTICAL ANALYSIS:}

Statistical analyses were done with the help of statistical methods of Mean, Standard Deviation and t- test. 


\section{The International Journal of Indian Psychology: Volume: 01 | Issue: 04 | ISSN 2348-5396}

\section{RESULTS:}

Table-1 shows the comparison of depressive and O.C.D patients on personality Inventory. The result found no significance difference in comparison between depressive and O.C.D. patients on personality inventory. Table- 2 shows the comparison of depressive and O.C.D patients on various dimensions of personality. The result found no significance difference in all the dimensions of personality inventory between depressive and O.C.D. patients. Table-3 showing the comparison of depressive and O.C.D patients on overall emotional maturity Scale. The result found no significance difference in overall emotional intelligence between depressive and O.C.D. patients. Table-4 shows the comparison of depressive and O.C.D patients on various dimensions of emotional maturity scale. The result found significant difference under the dimensions of emotional progression $\left(\mathrm{t}=2.15^{*}, \mathrm{P}<0.05\right)$ and independence $\left(\mathrm{t}=3.39^{*}, \mathrm{P}<0.05\right)$ which indicates depressive patients are more emotional progressed and less independent comparing with O.C.D. patients.

\section{DISCUSSION:}

The study found Depressive patients are more emotionally progressed (emotionally improve fast) comparatively than OCD patients. This may be because depressive Patients need to overcome their depression quickly so as to stop further negative consequences like - self harming, committing suicide, loss of confidence, feeling worst etc. Supportively, in earlier study Acharyya et al. (2012) found that female sexual workers are depress and in return becomes lonely comparatively other women of different professions. Furthermore, female sexual workers who are depress and lonely were less likely to compel their customer to use condom than those female sexual workers who are not depress and lonely. Srividya and Venkatammal (2012) mentioned in their study that Depression refers to feeling of despair and hopelessness, negative shifts in perception and decrease interest in activities that once provided pleasure. Bhattacharjee (2013) enlighten that major depression is a well documented risk factor for suicide in cancer patients as well as in the general population.

The study also acknowledges that Depressive patients are emotionally less independent comparatively than OCD patients. This may be because depressive patients feel low mood, poor social support, low self-esteem and dissatisfaction with intimate relationships so in turn they become less independent emotionally. Supportively, Srivastava (2011) proclaim in his study that Depression is an emotional illness with variable low mood that occasionally become positive and excited or cheerful. Sharma et al. (2012) found in their study that Depress patients in elderly have poor perception of social support than to those of normal group of elders. Hogg et al. (1994) found that Depress patients have low self-esteem and become dependent on others for day today activities and emotional support. Depress patients fail to establish autonomous stances during communication and dissatisfaction with intimate relationships (Kobak \& Gillies, 1995).

\section{CONCLUSION:}

The study concluded that Depressive and OCD patients did not differ significantly on personality and its various dimensions - Activity-Passivity, Enthusiastic-Non enthusiastic, Assertive-Submissive, Suspicious-Trusting, Depressive-Non depressive and Emotional instability- Emotional stability. They were found to be alike in respect of their personality. 


\section{The International Journal of Indian Psychology: Volume: 01 | Issue: 04 | ISSN 2348-5396}

Whereas Depressive patients were found to have obtained higher mean scores on Emotional progression (emotionally improve fast) dimension of emotional maturity but the OCD patients had higher scores on Independence dimension of the emotional maturity indicates depressive patients are more emotional progressed and less independent comparing with O.C.D. patients.

\section{REFERENCES:}

1. Acharyya, A., Modak, S., \& Majumder, S. (2012). Depression and loneliness among the Female sex workers in Tirupati. Journal of Psychological Researches. 56 (1), 15-20.

2. Bhargava, M., (1997). Dimensional personality inventory (DPI), Nandini Enterprisese, Agra, India.

3. Bhattacharjee, A. (2013). Who is more suicidal? A study among cancer patients with special reference to Tipupati. Indian Journal of Health and Wellbeing, 4 (4), 802-805.

4. Gopani, B.G. (2013). Emotional intelligence among Professors of granted and non granted colleges: A comparative study. The International Journal of Indian Psychology, 1 (1), 83-89.

5.Hogg, K.E., Goldstein, L.H., \& Leigh, P. N. (1994). The psychological impact of motor neurone disease. Journal of Psychological Medecine, 24 (3), 625-632.

6. Kobak, R. Gillies, R.F (1995). Emotion regulation and depressive symptoms during adolescence: A functionalist perspective. Development and Psychopathology, 7, 183-192. 7. Menon, P. (2011). Management of stress and enhancement of emotional intelligence in IT professionals through positive therapy. Indian Journal of Positive Psychology, 2 (2), 14-19. 8. Sen, S., Burmeister, M., \& Ghosh, D. (2005). 5-HTTLPR and anxiety-related personality traits meta-analysis revisited: Response to Munafo and colleagues. Retrieved from: http://scholar.google.co.in/citations?view_op=view_citation\&hl=en\&user=6zDiVKoAAAAJ\&ci tation_for_view=6zDiVKoAAAAJ:YsMSGLbcyi4C on 8/4/2014.

9. Sharma, M.P., Sunny, K.J., Mukundan, C.R. \& Chaturvedi, S.K. (2012). Social support and Quality of life in Depressed elderly. Amity Journal of Applied Psychology, 3 (1), 123-128.

10. Singh, Y., \& Bhargava, M. (1991). Emotional Maturity Scale (EMS). Applied and community Psychology, 2. Retrieved from:

www.ssmrae.com/admin/.../c97ef4fd50416f3d5e80ef6233d02e76.pdf on 8/4/2014

11. Sinha, A.K.P., \& Singh, R.P. (1995). Adjustment Inventory for College Students (AICS). National Psychological Corporation, Kacheri Ghat, Agra: India.

12. Srivastava, A. (2011). Depression in coronary heart disease patients. Indian Journal of Health and Wellbeing, 2 (2), 507-509.

13. Srividya, G., \& Venkatammal, P. (2012). Effectiveness of Cognitive Behaviour Therapy in Reducing Depression among Female Sopuses of Stroke Survivors. Journal of Psychological Researches, 56 (1), 78-83. 
The International Journal of Indian Psychology: Volume: 01 | Issue: 04 | ISSN 2348-5396

Tables:

Table-1 shows the comparison of depressive and O.C.D patients on personality Inventory.

\begin{tabular}{|l|l|l|l|l|}
\hline Group & N & Mean & S.D. & t-test \\
\hline Depressive Patients & 30 & 69.59 & 6.18 & \\
\hline $\begin{array}{l}\text { Obsessive Compulsive } \\
\text { Disorder Patients }\end{array}$ & 30 & 69.82 & 10.08 & 0.23 \\
\hline
\end{tabular}

** Significant at 0.01 level

*Significant at 0.05 level

Table-2 shows the comparison of depressive and O.C.D patients on various dimensions of personality inventory.

\begin{tabular}{|c|c|c|c|c|}
\hline $\begin{array}{l}\text { Dimensions } \\
\text { of } \\
\text { Personality }\end{array}$ & Group & Mean & S.D & t-test \\
\hline \multirow{2}{*}{$\begin{array}{l}\text { Activity- } \\
\text { passivity }\end{array}$} & Depression & 11.09 & 2.37 & \multirow{2}{*}{0.35} \\
\hline & OCD & 10.81 & 3.63 & \\
\hline \multirow{2}{*}{$\begin{array}{l}\text { enthusiastic- } \\
\text { non } \\
\text { enthusiastic }\end{array}$} & Depression & 7.70 & 3.03 & \multirow[t]{2}{*}{0.73} \\
\hline & OCD & 8.30 & 3.24 & \\
\hline \multirow{2}{*}{$\begin{array}{l}\text { assertive- } \\
\text { submissive }\end{array}$} & Depression & 10.99 & 2.61 & \multirow[t]{2}{*}{1.33} \\
\hline & OCD & 11.91 & 2.67 & \\
\hline \multirow{2}{*}{$\begin{array}{l}\text { suspicious- } \\
\text { trusting }\end{array}$} & Depression & 11.49 & 2.46 & \multirow[t]{2}{*}{1.76} \\
\hline & OCD & 12.69 & 2.76 & \\
\hline \multirow{2}{*}{$\begin{array}{l}\text { depressive- } \\
\text { non } \\
\text { depressive }\end{array}$} & Depression & 13.41 & 2.01 & \multirow[t]{2}{*}{1.66} \\
\hline & OCD & 12.40 & 2.61 & \\
\hline \multirow{2}{*}{$\begin{array}{l}\text { emotional } \\
\text { instability- } \\
\text { emotional } \\
\text { stability }\end{array}$} & Depression & 15.49 & 3.00 & \multirow[t]{2}{*}{0.25} \\
\hline & OCD & 13.59 & 2.97 & \\
\hline
\end{tabular}

Significant at 0.01 level

*Significant at 0.05 level 
The International Journal of Indian Psychology: Volume: 01 | Issue: 04 | ISSN 2348-5396

Table-3 shows the comparison of depressive and O.C.D patients on overall emotional maturity Scale.

\begin{tabular}{|l|l|l|l|l|}
\hline Group & N & Mean & S.D. & t-ratio \\
\hline Depressive Patients & 30 & 155.50 & 18.39 & \\
\cline { 1 - 3 } $\begin{array}{l}\text { Obsessive Compulsive } \\
\text { Disorder Patients }\end{array}$ & 30 & 161.91 & 21.21 & \multirow{2}{*}{1.24} \\
\hline
\end{tabular}

** Significant at 0.01 level

*Significant at 0.05 level

Table-4 shows the comparison of depressive and O.C.D patients on various dimensions of emotional maturity scale.

\begin{tabular}{|c|c|c|c|c|}
\hline $\begin{array}{l}\text { Dimensions of } \\
\text { emotional } \\
\text { maturity }\end{array}$ & Group & Mean & $\begin{array}{l}\text { S.D. } \\
\text { national }\end{array}$ & t-test \\
\hline \multirow{2}{*}{$\begin{array}{l}\text { Emotional } \\
\text { Maturity }\end{array}$} & Depression & 35.41 & 3.99 & \multirow{2}{*}{0.18} \\
\hline & OCD & 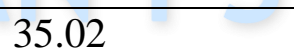 & 4.95 & \\
\hline \multirow{2}{*}{$\begin{array}{l}\text { Emotional } \\
\text { Progression }\end{array}$} & Depression & 35.61 & 4.29 & \multirow{2}{*}{$2.15^{*}$} \\
\hline & OCD & 33.01 & 4.98 & \\
\hline \multirow{2}{*}{$\begin{array}{l}\text { Social } \\
\text { Adjustment }\end{array}$} & Depression & 28.19 & 7.95 & \multirow{2}{*}{1.20} \\
\hline & OCD & 30.41 & 6.15 & \\
\hline \multirow{2}{*}{$\begin{array}{l}\text { Personality } \\
\text { Integration }\end{array}$} & Depression & 35.21 & 4.44 & \multirow{2}{*}{0.85} \\
\hline & OCD & 37.19 & 5.13 & \\
\hline \multirow[t]{2}{*}{ Independence } & Depression & 22.70 & 4.53 & \multirow[b]{2}{*}{$3.39 *$} \\
\hline & OCD & 26.90 & 4.98 & \\
\hline
\end{tabular}

** Significant at 0.01 level

*Significant at 0.05 level 